\title{
Motivations and consequences of secret contraceptive use among young married women in Malawi
}

\author{
Benjamin Kaneka and Akim J. Mturi \\ School of Research and Postgraduate Studies, Faculty of Human and Social \\ Sciences, North-West University (Mafikeng Campus) \\ bkaneka@cc.ac.mw / benjakaneka@yahoo.co.uk
}

\section{Abstract}

Studies have revealed that there are situations when a married woman would want to use contraceptives, but faces opposition from a partner or family members. Some of these women attest to using contraceptives secretly. The study investigates what motivate young married women to be engaging in secret contraceptive use. It also explores the risks and consequences of that practice in Malawi. The study uses qualitative approach. Thematic content analysis technique was used. The motivations to use contraceptives secretly were mainly driven by external factors and not inherently for the woman to exercise her denied sexual and reproductive rights. These include poverty and a quest to safeguard their marriages from instability and dissolution. The study concludes that involvement and inclusion of marital partners as target groups in the designing of family planning information and service provision is critical in increasing overt contraceptive use among young married women so that there should be no need for secret use.

Keywords: Secret contraceptive use, family planning, young married women, Malawi.

\section{Résumé}

Les études ont révélé qu'il y a des situations où une femme mariée voudrait utiliser la contraception, mais fait butte à l'opposition du partenaire ou des membres de la famille. Certaines de ces femmes témoignent de l'utilisation secrète de contraceptifs. L'étude examine les motivations pour les jeunes femmes mariées engagées ou mariées d'utiliser secrètement la contraception et explore les risques et les conséquences de cette pratique au Malawi. L'étude utilise une approche qualitative. La technique de la thématique contenue d'analyse a été utilisée dans l'analyse des données. Les motivations d'utiliser des contraceptifs secrètement on étés principalement poussées des facteurs externes à la femme. Ceux-ci sont notamment la pauvreté et la sauvegarde de leur mariage face à l'instabilité et de la dissolution et non intrinsèquement à la femme d'exercer son droit de control de sa sexualité et à la reproduction. L'étude conclut que la participation et l'inclusion 
de partenaires comme des groupes cibles dans la conception de la planification familiale restent des éléments essentiels dans l'augmentation de l'utilisation des contraceptifs chez les jeunes femmes mariées pour éviter leur utilisation secrète.

Mots-clés: utilisation de la contraception secrète, la planification familiale, les jeunes femmes mariées, Malawi

\section{Introduction}

The levels of fertility among young women aged 15-24 years in Malawi are high. For example, the latest nationally representative Demographic and Health Survey of 2010 found that there were 152 and 269 births per 1000 women aged I519 and 20-24 respectively. It was also found that by their $20^{\text {th }}$ birthday; about $64 \%$ of women had already started the childbearing process, $57.2 \%$ had at least a live birth, while $6.5 \%$ were pregnant with their first child. The median age at first birth was 18.9 years. Close to $34 \%$ of all births had occurred among young women aged 15-24. This means that fertility of young women disproportionately contribute to the country's high total fertility rate of 5.7 per woman. While almost all (99\%) women aged I5-24 are aware of modern contraceptive methods, only $26 \%$ and $38 \%$ of married women aged 15-19 and 20-24 respectively use modern contraceptives (NSO \& ICF Macro, 20II).

In spite of the scaling up of programme interventions aimed at increasing knowledge, induce positive attitudinal change and enhance male motivation to participate in contraception, partner opposition remains one of the most prominent barriers to contraceptive use among married women in Malawi (NSO \& ICF, 20II). In relation to unmarried women, studies have also revealed that there were overall unfavourable perceptions and opposition to their contraceptive use particularly from parents and teachers.

Partner opposition can be for contraception in general or for particular types of contraceptives. Partner opposition can be inimical to women's desires to be in control of and enjoy their sexual and reproductive health and rights. Under such circumstances, studies have shown that some women use contraception secretly (Kinaro, 2015; Decker \& Constantine, 20II; Castle et al, 1999; Zulu, 1998). Secret contraceptive use in this study is restricted to the use of contraceptives by a young married woman without the knowledge of her husband (Biddlecom \& Fapohunda, 1998).

However, in Malawi, there is dearth of studies that have investigated contexts and factors that would motivate a young married woman to engage in secret contraceptive use. It is also not clear what risks are associated with such course of action by these young married women who are in the early stages of their marital and reproductive lives. It is pertinent to investigate and understand these phenomena because secret contraceptive use can have a bearing on contraceptive method choice, and initiation, continuation and switching of the chosen method and 
the overall levels of contraceptive practice. The study is anchored on the assertion that young married women's current sexual and reproductive behaviour would have a bearing on the future demographic fertility direction of a country as a whole.

\section{Study Objectives}

The overall objective of the study is to investigate the contexts and motivations for secret contraceptive use among young married women in Malawi. Specifically, the study is geared to:
a) investigate the young women's motivations for secret contraceptive use; and
b) explore the implications of secret contraceptive use among young married women.

\section{Research Questions}

i. What is the motivation for secret contraceptive use?

ii. What are the strategies used in hide secret contraceptive use?

iii. What are the challenges of secret contraceptive use?

iv. What are the risks of secret contraceptive use?

\section{Literature Review}

Some studies have proffered explanations as to what motivate married women to engage in secret use of contraceptives. They have concluded that some women opt for secret contraceptive use because of the gender inequalities that ensue in the family whereby husbands yield powers to make decisions in most of the domestic issues particularly so in matters of sexuality, childbearing and contraception. Further, other women indicated that they find issues of sex and contraception too embarrassing to even be discussed at all (Biddlecom and Fapohunda 1998; Castle et al, 1999; Kinoshita, 2003). Under those circumstances, it was contended that the woman would rather resort to secret use to meet her contraceptive needs at that particular time when the situation is not conducive for her to engage her partner on such a sensitive issue or use contraceptives overtly. (Chipeta et al, 2010; Hartmann et al, 2012; Chimbiri, 2007). Some studies have concluded that women would engage in secret contraceptive use to safeguard the health and economic welfare of their children (Biddlecom \& Fapohunda, 1998; Decker \& Constantine, 20II). In addition, other studies have found that secret use is more prevalent in situations where there is reported physical violence between spouses in the family than otherwise (Bogale et al, 20II; Stephenson et al, 2008).

Secret contraceptive use was also found to determine and limit the choice of contraceptive methods to be used and was linked to the predominant use of specific contraceptive methods. In a study in Malawi (Bisika 2008), it was found that a majority of women had used the injectables because it afforded them some degree of control over its use, was convenient as it would be taken periodically after three months and it was a method that could be easily used without the knowledge of the husband and others. In Zambia, Biddlecom and Fapohunda (1998) found that women who indicated that they were using contraceptives 
without their husbands' knowledge were using methods that could be easily hidden including periodic abstinence. In Kenya, Magadi and Curtis (2003) found that women whose partners disapprove of family planning were more likely to use traditional methods. A study among young people in Uganda (Nalwadda et al, 2010) also revealed that most young women who were using contraceptives secretly relied on the injectables because it was easy to conceal the fact that they were using a contraceptive method. Use of injectables was also found to be popular in Ghana, Madagascar and Tanzania (Adetunji, 20I I). Studies revealed that secret contraceptive use has risks and adverse consequences. The most prominent are fears that the secret use can be discovered by partners because of the side effects that can ensue. For example, the perceived side effects such as irregular and heavy menstrual flow that may result from use of hormonal methods such as injectables were particularly worrisome to women. As they interfere with the normal sexual relations with their spouses, there were fears that their secret contraceptive use could be easily discovered (Biddlecom and Fapohunda, 1998; Castle et al, 1999).

The cited studies have focused on all women or young unmarried women. By focusing on young married women who are in the early stages of their marital and reproductive years, the study fills that lacuna in knowledge.

\section{Data sources and methods}

The study participants were purposively selected from the districts of Zomba, Ntcheu and Mangochi in Malawi. These districts reflect the demographic, social and cultural diversity of the country. Data were collected from purposively selected young married women through 68 individual in-depth interviews (IDI) and 216 discussants in 18 focus group discussions (FGDs) of 12 members each. The FGDs were conducted for young (15-19) and older women (20-24) separately. Both IDIs and FGDs were conducted in Chichewa (the national local language) and were audio taped after obtaining verbal consent from the study participants. The taped IDIs and FGDs were transcribed verbatim and translated into English. The data were analyzed using thematic analysis method that involves the creation and application of codes to data (Gibson, 2006). The scripts (documents) were uploaded into computer software called Atlas Ti Version 7 (Mohamad, 2014) that assisted to easily code the textual data using the predetermined themes and do further analysis. The results are presented through the selection of associated quotes that best capture the substance of the themes and answer the research questions.

One limitation is that the study's focus was on young married women whose perceptions and experiences were being investigated and captured. However, in the FGDs and IDls young married women also expressed their perceptions about men's attitudes and behaviours pertaining to contraceptive use. It would have been more enriching to explore the perceptions and experiences of the young married women's partners or men in general on these matters to confirm or dispute the women's narratives. 


\section{Study Findings}

\section{Motivation of secret contraceptive use}

The results show that a majority of young married women (from 12 FGDs and 39 IDIs) expressed positive attitudes and were in favour of secret contraceptive use under certain circumstances. However, participants revealed that secret contraceptive use was such a painstaking and risky endeavour that could only be embarked on under extremely desperate situations and with very strong motivations. The following section highlights what study participants proffered as motivations for secret use.

\section{i) Fear of abandonment}

Although one of the adverse consequences of secret use (as highlighted in the appropriate section below) is that a married young woman can be abandoned for another woman once her secret contraceptive use is discovered by her husband, it was intriguing to note from the study results that there were some young married women who indicated that they have used contraceptives secretly in order to keep their bodies in shape so that their husbands should not abandon them for other women due to incessant childbearing and its effect on their body shape and physical appearance. It was apparent from the study participants that their clandestine use was motivated by the quest to keep their husbands attracted to them hence safeguarding their marriages. In addition, they also wanted their men not to stray to other women more particularly during the traditionally sanctioned long waiting period between child birth and the resumption of sexual intercourse that can range from 6 months to 2 years. There were common assertions among young married women in the study that constant childbearing and having many children make their bodies to deteriorate such that they would be looking too old for their ages.

We know that they would abandon us because they want younger women. Some of us use contraceptives in secret to ensure that our men do not to run away. They should be happy with the way we look and they should enjoy sex. [FGD: 20-24, Ntcheu].

I started using contraceptives without his knowledge because I noticed that if I give birth more often the result would be that my husband will not love me anymore. Now that I use contraceptives, we are able to enjoy sex in the house. We have sex freely. We are happy. [IDI: 22, one child, user, Zomba].

When one gives birth to many children and the childbearing is done often and the man sees that he has given you many children, he leaves you and the marriage ends there. So we just decided to go for these methods anyway. In this way we keep our marriages. [FGD: 20-24, Zomba].

We are always told by our grandmothers that when a woman has given birth, she has to abstain for 6 months. However, at the hospital they are saying after 6 weeks we can resume sex. It happens that at home; the husband would be pestering the wife after that period of 6 weeks. In order not to refuse, she sneaks out to a clinic so that when having sexual intercourse with him, she is already on a 
method to prevent getting another pregnancy while the child is still small. [FGD: 20-24, Ntcheu].

\section{ii) Reaction to marital instability}

The study revealed that some young married women had used contraceptives clandestinely as a reaction to the adverse marital environment in which they found themselves. It was clear from their narratives that they would not want to continue childbearing in a marital environment that was hostile and unstable. It was also found that this instability would be triggered by their men's mistreatment of their wives and children and promiscuity. However, it was clear during the discussions that this clandestine use was not meant to fight back on their husbands' misbehaviours, but rather as a precautionary measure in a marriage that was breaking. There were expressed fears that continued childbearing would turn out to be disadvantageous to them, as mothers with small children, as they might be left taking care of many children in the event of a marital dissolution arising from the marital instability. The following sentiments were expressed by participants:

It is just ill-treatment from men. You have to be clever to only have two children and manage to support them even if he divorces you. [IDI: 22, 2 children, user, Zomba].

When my friend noticed that her husband had started going out, she knew that she will end up with many children with a man who is not good. This made her to start using contraceptives secretly. [IDI: 20, I child, user, Ntcheu].

When the man indulges in promiscuous behaviour, with your contraceptive use you are not worried much with this. You leave him to do what he is doing because you know that you are taking contraceptives and that you can't conceive. [FGD: 20-24, Mangochi].

iii) Lack of spousal communication

The young married women in all the districts discussed the difficulties they encountered in their quest to initiate and engage in discussions with their husbands on many issues let alone those pertaining to sex, childbearing and contraception. Although the reasons for these difficulties were not clear from these discussions, it could be surmised from their narratives that there decision making powers are in the hands of men, as heads of the families. Young married women expressed sentiments to the effect that any attempt to have such discussions would raise doubts about their characters and would be construed as a sign of bad external influence from relatives or wayward friends. What became clear in their narratives was that this secret use was somehow triggered by lack of alternatives to carter for their needs for contraception of some sort at a particular point in time and lack of opportunities to engage their husbands on the same. There were expressed sentiments that the lesser evil for them was to use contraceptives secretly than risking engaging in a discussion on issues that would invoke suspicions and tensions in the family. These 
sentiments are discerned from these quotes:

We are afraid that if we tell them about contraceptives, they become a problem. They would not allow us to go ahead with our plans. That's why we use these contraceptives without their knowledge. We do this secretly. We use injections. Our husbands just see that the pace of childbearing is slowing down. [FGD: 2024, Ntcheu].

Some men are always furious and very tough. For us to discuss contraception with them, it is a problem. They just go out while they are angry and for us to have courage and talk more to them, we fail. They would say 'what are you saying? Are you the one who is feeding these children? I am the bread winner, so what are you saying?" You then just know what to do on your own. [FGD: I5-19, Zomba].

As a woman you are always afraid of the husband who will question where such ideas are coming from. This can go to the marriage counsellors or sometimes he can even beat you up. In these cases, you are forced not to mention or discuss the issue with him, but just sneak out and do it yourself. [IDI: 2I, two children, user, Zomba].

iv) Inadequate household support

It was established in the study that young married women felt they were justified in secret contraceptive use when their husbands were unable to support them and take care of the already born children due to laziness or drunkenness. In all the study districts, the clandestine use of contraception was found to be a way of limiting additional births that would add to the economic burden of their families. However, in matrilineal communities of Zomba and Mangochi, the study participants further indicated that secret contraceptive use would limit the extra burden shouldered by the young woman and her extended family since culturally children belonge to the woman's family and clan and the man would leave the children behind upon marital dissolution. Their sentiments illustrate that stand:

We tell them about contraceptives, but they refuse to hear about it. So looking at the problem of raising many children, we just sneak out and get the methods. [FGD: 20-24, Zomba].

The man who gave you the children is failing to support you and the children. I want the children to grow in good health. I would rather go for contraceptive methods on my own than face poverty problems. [IDI: 23, 3 children, user, Mangochi]

Some husbands are just drunkards who only know how to sire children but fail to support them. They go out to drink daily. Looking at the level of poverty in the family, we just go for family planning alone to have a small number of children. [FGD: 20-24, Mangochi].

v) Uncertainty over husbands' return dates It became apparent during the study, particularly in Mangochi and Ntcheu districts, that many young men often migrate to South Africa to seek employment and stay there for two or 
three years leaving their young wives at the homes of the men's parents. However, because of the temporary and fluid nature of their informal employment tenure in South Africa, these young men can come back home at any time. It was learnt during the study that young married women, particularly those who have small babies, would use the contraceptives secretly so that should their husbands return suddenly, they should not fall pregnant prematurely while the baby was still small. However, they indicated that this could land them in serious problems, including being chased away from the husband's parents' place if discovered. It was found that they would be accused by their men's family members of engaging in extra marital sexual relations even in the absence of any proof. The subsequent quotes highlight those sentiments:

Your husband may come from South Africa just suddenly while you are breastfeeding and will need to sleep with you. If you had not used contraceptive methods, then it's likely you will get pregnant. But when people see you using contraceptives, they think you are just doing this to be engaging in promiscuity. [IDI: 19, I child, user, Mangochi]

Most men in this community go to South Africa in search of greener pastures leaving behind their pregnant spouses. Soon after giving birth, some women go for a contraceptive method because they do not know when the husband would show up. When people see that woman, they think that this woman is promiscuous 'why is she taking methods when the husband is abroad? [FGD: 20-24, Ntcheu]. vi) To safeguard own health

While husbands have, as discussed above, culturally more powers in sexual and reproductive decision making and practices in marital unions, the study participants indicated that the burden of suffering from the physical and emotional costs of pregnancy and childbearing was disproportionately placed on the shoulders of women. In this respect, interviews with young married women revealed that they are motivated to go for secret contraceptive use in order to safeguard their health. They indicated that their general health deteriorates due to pregnancy induced conditions such as high blood pressure and anaemia that emanates from loss of blood during delivery. These sentiments were captured thus:

It happened to me. I saw that this will not help me. It is me who gives birth. The end of it is that I will have problems. I just started it alone behind his back, without his knowledge so that I stay in good health. But it is better that I am assisted because I am the one who suffers birth pains while he is seated at home. [IDI: 23, 2 children, user, Ntcheu].

Your man goes back home leaving you at the entrance to the labour ward; you are the one who experiences problems in the labour ward. It is not good to have children every year and losing blood. This idea of using contraceptives secretly is the way to preserve your life. [IDI: 2I, 3children, user, Zomba].

Most of these husbands are so stubborn that they do not want a woman to go for 
family planning methods. All they think about is having children yearly without considering the problems caused on the woman. As a child bearer, I just do what I feel is good for me as far as my health is concerned [IDI: 20, I child, user, Mangochi].

v) Negative attitude towards secret contraception

It was evident from the discussions and interviews that there were mixed feelings about the essence of secret contraceptive use among young married women. While some were in agreement with secret use under certain circumstances, there appeared also opposition to any secret contraceptive use regardless of the justifications; describing it as a sign of disrespect for the husband and equated it to open confession of engaging in extra marital sexual liaisons. These sentiments are aptly captured in these subsequent excerpts:

These women who use contraceptives secretly have relationships outside their marriages, so in order for their partners not to know what they are doing, they use contraceptives in hiding to be free to go out with other men. She just says "I am going to the bus depot, while she knows that she has an appointment with another man". [FGD: 20-24, Ntcheu].

There is no reason for contraceptive use if the husband went to Johannesburg' because she is not having sex with any man. But because she wishes to be wild as the

\footnotetext{
I Johannesburg is a big city in the Republic of South Africa that attracts economic migrants

man is far, she doesn't want to be caught that she was messing up. So for her she feels it is good to go and get a secret injection in order not to get pregnant. [IDI: 20, 2 children, user, Ntcheu].

We, as onlookers, would know that she is practicing prostitution and what she is afraid of is pregnancy. By practicing family planning, she is promoting her prostitution. [FGD: 20-24, Mangochi].

\section{Strategies for hiding use}

It was apparent from the young women's discussions and narratives that clandestine use required effective strategies that would reduce the chances of being discovered by the husband or other family members. These strategies included hiding their visits to health centers, avoiding being seen at the health centers and hiding any family planning information that would give them away as secret users. These fears of being discovered were common and compelled young married women to go to great lengths to ensure that their contraceptive use is kept a secret. The results also show that there was collusion between young married women and some service providers whereby the later would assist in hiding contraceptive use from the young women's husbands. One of the most prevalent strategies was the maintaining of two health passport books where one is for family planning, while the other is for general health. It was revealed that when they visit health centers for contraceptives, they would agree with the service providers to keep the family planning

from all the countries in Southern Africa region.. 
books for them at the health centers, while they take the general health passport books home to show to their husbands. The following quotes aptly summarize these strategies:

My husband did not allow me to practice family planning, but I managed to do that secretly. I bought a book which I would leave at the hospital whenever I visit the hospital and have Depo injection secretly. If there is another method which my husband can't be involved in apart from the injection, I would love to use that method after I deliver this child. [IDI: 24, 2 children, Ntcheu].

You go to the hospital and explain your situation to the doctor. The doctor provides a paper so that when you have your injection you leave the paper right there at the hospital, even the health passport book, you leave it there, they keep all those for you. [FGD: 15-19, Zomba].

The health passport books where records of family planning are found are left at the health centre so that husbands should never see them. Sometimes they are hidden where baby nappies are kept. When the appointment is due, we feign illnesses so that the husbands are hoodwinked into believing that we have gone to the clinic to access treatment for an illness [FGD: 20-24, Ntcheu].

It was also revealed that at times friends, neighbours and sisters could be used to hide any evidence of the secret use. These were trusted women within the young married woman's circle of confidants who are also sources of information about contraceptive experiences and opinions about particular methods. They use the same strategy of using two health passport books with the contraceptive one being kept at a relative or friends' place.

It happens like that because other men do not like their spouses to use contraceptives so women make a plan of having two health passport books, so that the nurses should be recording the contraceptive use in another book and you keep it at your neighbour. [FGD: 20-24, Mangochi].

You can as well keep the health book for family planning at your friend's house whom you know that she will keep it as a secret. [IDI: I8, I child, user, Ntcheu].

\section{Challenges of secret use}

The study results revealed that there are a number of challenges associated with secret contraceptive use. These most prominently mentioned ones were limited contraceptive choices and side effects.

i) Limited contraceptive method choices

It was noted that, in spite of their side effects, most clandestine users use injectables. They proffered reasons for the preference of this method. They indicated that the method's administration ensures greater secrecy as it does not require them to carry any commodities home as is the case with other methods such as pills (Adetunji, 20I I). More importantly, it was said to be the most secretive method that can be hidden easily from their husbands or other members of the family. It is a method 
that is administered once in three months as such they would not be required to visit the clinic regularly and risk being discovered and that it is a short term method that can be easily discontinued if one needs to conceive again. The other methods such as the pill and Norplant were also mentioned by the participants, but it was clear that they were not as favoured because of the likelihood of being easily discovered by partners. The pill was said to be highly demanding because it has to be taken daily and also that one can easily forget the pills at a place where the partner can easily see and ask about them. As for Norplant, it was said that the conspicuous marks on the woman's upper arm can be easily noticeable and give the woman away when questions are asked. It was also said to be a long acting method which they indicated might be difficult to reverse if desired so.

\section{ii) Side effects}

It was apparent from the discussions that young married women were always worried about the possible side effects of the injectables as their chosen method for secret contraceptive use. The concerns mainly centred on the disruptions in the menstrual cycle, caused by the injectables that at times could lead to prolonged bleeding, spotting or amenorrhea. While they expressed concerns about these effects on their health, it was noted that their worries were much more to do with fear of being discovered. It was also revealed that even if the effects may be taking a toll on their health or comfort, the young married women would still persevere and be hesitant to tell their husbands or seek treatment for the problem. It was also indicated that because the husband is not aware of the woman's contraceptive use, it could cause a great deal of consternation on the part of the man as he would be going about looking for treatment for his wife's purported illness.

The discussions also centred on the cultural beliefs pertaining to menstruation. It was established that prolonged spotting or bleeding would restrain young married women's husbands from having sexual intercourse with them as it was culturally prohibited for a man to have sex with a menstruating woman. In addition, it is also culturally believed that a menstruating woman should not put salt into food lest she brings in serious illnesses (for example swollen feet) that can affect everybody in the family. Thus, constant spotting or bleeding may alert not only the husband, but other family members about her secret use as she would not be able to perform her sexual as well as social functions. Likewise, prolonged amenorrhea due to contraceptive use would lead one's husband to suspect that the wife might be pregnant or has been affected by an illness. These situations are aptly illustrated in the following statements from the study participants:

For one to start using contraceptives without the knowledge of the husband, this is a problem, because some women when they use injection method they experience continuous bleeding throughout the month. It becomes difficult to tell their husbands the cause of the abnormal menses. The husband would start to consult traditional healers in different places thinking that the woman has been 
bewitched while she knows that it is this injection she is using which has caused all that. It's like you confuse the husband instead of just being open to him and tell him the truth. [FGD: 20-24, Ntcheu].

It may be good to sneak and go for injection for contraception, but it does not always go well with some women. They experience continuous bleeding and husbands find it hard to sleep with them. Some husbands would tell their parents or the woman's parents to investigate the cause of the problem and because of fear of worsening the matters; you just disclose that you went for contraception. [IDI: 20. 2 children, non user, Ntcheu].

Sometimes one would experience problems due to the use of contraceptives, maybe one falls very sick due to heavy menstruation. You fail to tell your husband that the sickness is from the use of contraceptives because you are taking them without his knowledge. Had it been that the husband was aware of this, you would have discussed this issue properly and the husband would have taken you to the hospital where you can be helped. [FGD: 20-24, Zomba].

Maybe one has injection and experiences continuous bleeding which occurs daily from first day of the month to the last day. So if the husband wants sex, it happens that this fails because the wife always says "I am on my period", so the husband says "why is it that you are experiencing continuous periods in all these days, you were not experiencing this before". As a result you reveal it to him yourself that you are using injections and things turn sour. [FGD: 20-24, Mangochi]

The other challenge as noted in the study emanated from young married women's misunderstanding of the reasons for sexual abstinence of between 4 and 7 days they indicated to have been advised by the service providers when they get injections as a contraceptive method for the first time. While the reason might be to allow the drugs to settle in the woman's body and become more effective, it was noted that the study participants interpreted that to mean that the drug was so powerful such that without observing that period, the potency of the drug could actually harm the man's sexual organs rendering them too weak to function. These fears of the purported side effects were expressed as a challenge to secret use because under normal circumstances, the husbands would have known why they had to abstain for those days. These scenarios are illustrated below:

Using contraceptives without the knowledge of the husband is problematic. When you receive instructions from the hospital that after getting the injection when you go home you should avoid having sex for four days, for us to refuse to have sex, we know that he will discover that you are using contraceptives. It so happens that you accept to have sex with him as a result the husband will have problems in his body because of the drug that is in the injection. [IDI: 23, 2 children, non user, Ntcheu].

We go for contraceptives without the knowledge of our husbands. We are given instructions that after taking this method, 
we should not have sex for some days, so back home, we fail to deny them sex when they want it, in so doing the drug in the woman destroys his manhood. [IDI: 20, 2 children, former user, Mangochi].

\section{Risks of secret contraceptive use}

It became clear from the study participants that young married women were always troubled in their decisions to use contraceptives clandestinely because of what would befall them once discovered by their husbands or family members. It was also found that there would be very little family support for young married women who take such a decision to go into secret contraceptive use. It was surmised that the young married woman would be rebuked by her family for acting as if she were not married or for going against her husband's rules, both of which were said to be unacceptable in marriage and indefensible even among her own family members. What became apparent in the discussions was that secret contraceptive use if discovered could put the woman and her whole family into shame since marriage, within the cultural context, was not about the two individuals but rather a union of two families. A young married woman in Mangochi explains this:

Everyone would be laughing at you for insisting on contraception contrary to your husband's wishes. This is not acceptable in marriage and can put the woman's own uncle (the clan head) and the whole family into shame such that they can't back your actions for whatever reason. [IDI: 24, 3 children, non user, Mangochi].
It was also found that there can be adverse consequences of secret contraceptive use once discovered. These included marital conflicts, withdrawal of support (abandonment) and even divorce. What could be discerned from the young married women's narratives was that husbands would feel undermined, threatened or betrayed. Husbands would feel loss of control over their wives and authority in the wider family matters. The excerpts below express those feelings:

Some husbands are so violent that they count the number of months to check if you are getting pregnant or not. They will force you to go to the hospital to have a check up. When they discover that you have been going behind their backs, accusations will arise because it is like they are being challenged. [FGD: 20-24, Ntcheu].

When the husband notices that you are not conceiving, he suspects that the wife is cheating on him. He thinks that maybe these children we have are not his. He would ask how come she is failing to conceive again. He would say "ooh those pregnancies were not mine; there is someone who impregnated her". The man ends the marriage because you are using contraceptives secretly and he feels worried about the intensions. [IDI: 23, 2 children, non user, Ntcheu].

\section{Concluding Remarks}

The results have shown that secret contraceptive use is one of the strategies young married women use to counter partner opposition to contraceptive use. It 
was clear from the results that secret contraceptive use had risks and consequences such that it could only be embarked upon when one is desperate. When a young married woman engages in contraceptive use without knowledge or approval of her husband, it was likened to challenging the authority of the husband and his control over his wife's sexual and reproductive realms as the head of the family. It became clear that young married woman's main motivations were mainly externally driven by factors such as poor family care (poverty), and ironically to safeguard thee marriage from instability and dissolution and not necessarily by the woman's desire and quest to meet and enjoy her sexual and reproductive health rights.

The issue of safeguarding their marriages takes the form of dissuading their husbands from seeking sexual gratification elsewhere under the pretext that their women were no longer sexually attractive due to constant childbearing. In other cases, it was in a quest to still provide sexual gratification to their husbands during the long wait (culturally a minimum of 6 months) before resumption of sexual liaisons after child birth. Related to this is the use of contraceptives secretly as a reaction to the husband's promiscuity and mistreatment and failure to provide support to the children. This was done to ensure that the young married woman would not be left with many children in the event of divorce. Secret contraceptive use was also found to be an option in situations where the woman would want to safeguard her health bearing in mind that the bulk of physical and emotional consequences of childbearing rests upon her shoulders. Further, young married women would go for the method secretly because of the difficulties in communicating their reproductive desires to their husbands due to fear of confrontation.

Fear of side effects particularly irregular menstruation was the commonest challenge faced by secret users. Their main concern was more about the disruptions that can cause to their husbands' sexual lives than their own health or convenience. The concern is also fear of being discovered by the husband or other family members with accompanied risks of marital conflicts, abandonment or divorce.

However, the study asserts that secret contraceptive use denotes the fact that not all young married women are passive victims of male control and that they always succumb to their husbands' sexual, reproductive and contraceptive decisions. In spite of its risks, opposition and pressure, secrete contraceptive use is a demonstration of some level of agency among young married women to act out their reproductive and contraceptive needs when need arises. These findings corroborate the results in a study among rural women in Malawi (Schatz, 2005) where it was found that women had the agency and capacity to divorce their husbands in a quest to protecting themselves from HIV in situations when the husbands were continually being promiscuous.

Nevertheless, it is recommended that efforts should be made to effectively include and involve partners as a target group in the national family planning 
programme through sustained advocacy and information, education and communication (IEC) interventions. This will entail that there would not be any need for these women to engage in secret contraceptive use out of desperation and lack of alternatives.

The study also proposes a model for family planning delivery in the country that will be empowering to young married women to achieve their sexual and reproductive goals through guaranteeing of utmost secrecy, privacy and confidentiality. This should involve being provided with special support they would require, as young married women, for their contraceptive practices and respect the choices they would make whether to use contraceptives overtly or covertly in the face of any opposition. The model for service delivery should include a policy of integrating family planning services with general medical health services so that confidentiality can be enhanced as opposed to the current practice of having family planning services provided at designated places and on particular days and times within the health facilities.

\section{References}

Adetunji, J.A. 20II. Rising popularity of injectable contraceptives in subSaharan Africa. African Population Studies, 25(2), 587-604.

Biddlecom, A.E. \& Fapohunda, B.M. 1998. Covert contraceptive use: prevalence, motivations, and consequences. Studies in family planning, 360-372.

Bisika, T. (2008) Cultural factors that affect sexual and reproductive health in Malawi. Journal of Family Planning and
Reproductive Health Care, 34(2), 7980.

Bogale, B., Wondafrash, M., Tilahun, T. \& Girma, E. 20II. Married women's decision making power on modern contraceptive use in urban and rural southern Ethiopia. BMC Public Health, II I I : 342.

Castle, S., Konate, M.K., Ulri, P.R. \& Matin, S. 1999. Qualitative Study of Clandestine Contraceptive Use in Urban Mali, Studies in Family Planning, 30(3): 23I-248.

Chimbiri, A. M. (2007). The condom is an 'intruder'in marriage: evidence from rural Malawi. Social science \& medicine, 64(5), II02-III5.

Chipeta, E. K., Chimwaza, W., \& KalilaniPhiri, L. (20/0). Contraceptive knowledge, beliefs and attitudes in rural Malawi: misinformation, misbeliefs and misperceptions. Malawi Medical Journal, 22(2).

Decker, M. \& Constantine, N. 20II. Factors Associated with Contraceptive Use in Angola, African Journal of Reproductive Health, 15(4): 68-77.

Gibson, W. (2006). Thematic Analysis. Retrieved 06/10/2015 from

http://www.ilit.org/air/files/thematic_a nalysis.doc

Hartmann, M., Gilles, K., Shattuck, D., Kerner, B., \& Guest, G. (20|2). Changes in couples' communication as a result of a male-involvement family planning intervention. Journal of health communication, I 7(7), 802-8I9.

Kinaro, J., Kimani, M., Ikamari, L. \& Ayiemba, E.H. 2015. Perceptions and Barriers to Contraceptive Use among Adolescents Aged 15-19 Years in 
Kenya: A Case Study of Nairobi. Health, 7(0I), 85.

Kinoshita, R.,(2003) Women's domestic decision-making power and contraceptive use in rural Malawi. Carolina Papers International Health, 14:I-113,. University Centre North Carolina at Chapel Hill.

Magadi, M. A., \& Curtis, S. L. (2003). Trends and determinants of contraceptive method choice in Kenya. Studies in family planning, 34(3), I49159.

Mohamad, A. . (20I4). Using ATLAS. ti 7 For Researching The Socio-Legal Implications Of ICT Adoption In The Justice System Of The High Courts Of Malaysia. S. Friese (Ed.). Universitätsverlag der TU Berlin.

Nalwadda, G., Mirembe, F., Byamugisha, J. \& Faxelid, E. 2010. Persistent high fertility in Uganda: young people's recount of obstacles and enabling factors to use of contraceptives. BMC Public Health, IO(I): 530-543.

NSO \& ICF Macro. 20II. Malawi Demographic and Health Survey 2010. Zomba, Malawi, and Calverton, Maryland, USA: National Statistics Office and ICF Macro.

Schatz, E. 2005. 'Take your mat and go!': rural Malawian women's strategies in the HIV/AIDS era. Culture, health and sexuality, 7(5): 479-492.

Stephenson, R., Beke, A. \& Tshibangu, D. 2008. Contextual influences on contraceptive use in the Eastern Cape, South Africa. Health \& place, 14(4): 84I-852.

Zulu, E. 1998. The role of men and women in decision-making about reproductive issues in Malawi: African Population Policy Research Centre. 